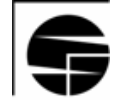

IIASA

A Structured Modeling Technology

Marek Makowski

RP-06-002

March 2006

RERINTIT 



\section{A Structured Modeling Technology}

Marek Makowski

International Institute for Applied Systems Analysis

Laxenburg, Austria

RP-06-002

March 2006

Reprinted from European Journal of Operational Research, 166(3): 615-648 (Article) and 593-596 (Editorial) (2005). 
IIASA Reprints make research conducted at the International Institute for Applied Systems Analysis more accessible to a wider audience. They reprint independently reviewed articles that have been previously published in journals. Views or opinions expressed herein do not necessarily represent those of the Institute, its National Member Organizations, or other organizations supporting the work.

Reprinted with permission from European Journal of Operational Research, 166(3): 615-648 (Article) and 593-596 (Editorial) (2005).

Copyright (C) 2004 Elsevier B.V.

All rights reserved. No part of this publication may be reproduced or transmitted in any form or by any means, electronic or mechanical, including photocopy, recording, or any information storage or retrieval system, without permission in writing from the copyright holder. 


\title{
A structured modeling technology
}

\author{
Marek Makowski * \\ International Institute for Applied Systems Analysis, Schlossplatz 1, Laxenburg A-2361, Austria
}

Received 1 September 2002; accepted 1 March 2004

Available online 1 September 2004

\begin{abstract}
This paper presents the methodological background and implementation of a structured modeling environment developed to meet the requirements of modeling activities undertaken to support intergovernmental negotiations aimed at improving European air quality. Although the motivation for the reported work came from the actual complex application presented in the paper, the actual scope of the paper covers a wide range of issues related to model-based decision-making support. The paper starts with a summary of the context of modeling composed of: the role of models in decision-making support; modeling paradigms; and state-of-the-art aspects of modeling complex problems. The modeling process is then characterized, and the requirement analysis for implementation of structured modeling is specified. The main part of the paper presents the structured modeling technology which was developed to support the implementation of the structured modeling principles for modeling complex problems.
\end{abstract}

(C) 2004 Elsevier B.V. All rights reserved.

Keywords: Structured modeling; Decision support systems; Modeling systems and languages; Model management; Simulation; Largescale optimization; Multiple-criterion optimization; Database management systems; Object-oriented programming; Internet; Environment 



\title{
Editorial
}

\section{Advances in Complex Systems Modeling}

\author{
Marek Makowski \\ International Institute for Applied Systems Analysis \\ Laxenburg, Austria \\ Yoshiteru Nakamori \\ Japan Advanced Institute of Science and \\ Technology, Kanazawa, Japan \\ Hans-Jürgen Sebastian \\ RWTH Aachen University, Aachen, Germany
}





\section{Editorial}

\section{Advances in complex systems modeling}

This Feature Issue of EJOR contains a selection of papers that were submitted in response to the open call for papers published in April 2002. The call defined the scope of the issue as follows: The feature issue focuses on innovative methods and tools supporting the entire life-cycle of model development, maintenance and analysis, including various modeling paradigms, techniques and tools. The methodology for modeling and analysis of complex systems includes optimization-based approaches, multi-criteria decision analysis, nonstandard simulation and multi-agent systems approaches. Modeling of uncertainty using uncertainty theories, such as probability theory, fuzzy set theory and possibility theory, is an integral part of the complex systems we are focusing on. Development of new methodologies is closely related to real world applications. Application areas of particular interest for this feature issue include telecommunication, production planning and scheduling, logistics, transportation, environmental policy-making, and electronic commerce. One particular focus is on virtual worlds and modeling, including distributed decision technologies and collaborative modeling.

Authors of papers presented at the two workshops listed below, were particularly invited to submit their full papers for this Feature Issue:

- The VEAM Workshop on Virtual Environments for Advanced Modeling, organized jointly by the IFIP Working Group 7.6. and the Japan
Advanced Institute of Science and Technology (JAIST) on 25-27 March, 2002, at JAIST, Kanazawa, Japan.

- CSM'02, the 16th JISR-IIASA Workshop on Methodologies and Tools for Complex System Modeling, organized jointly by the Japan Institute of Systems Research (JISR) and the International Institute for Applied Systems Analysis (IIASA) on 15-17 July, 2002, at IIASA, Laxenburg, Austria.

The VEAM Workshop was the eighth conference organized by the IFIP Working Group 7.6 Optimization-based Computer aided Modeling and Design. This Working Group is part of IFIP's TC 7 Technical Committee on System Modeling and Optimization, and considers high-performance computer-aided systems to support modeling, decision analysis, optimization and multi-criteria decision making support. The focus of the Working Group is on applications in policy and management. The Working Group has particular interests in the following types of problems: network design, planning and scheduling in transportation, traffic and telecommunication, production planning and scheduling, and environmental planning. The methodology used to solve these applied problem types is mainly located in the fields of optimization, simulation and multi-criteria decision analysis. Finally, the Working Group explores intelligent decision support systems 
designed to successfully deal with large scale and complex systems from policy and management.

The CSM'02 was the 16th workshop organized jointly by JISR and IIASA. The long-term collaboration between these two institutes has focused on the development of methodologies and tools needed for complex system modeling and integrated policy assessment, as well as on actual applications of such methods and tools. In particular:

- Innovative methods and tools supporting the entire life-cycle of model development, maintenance and analysis; various modeling paradigms, techniques and tools applicable for large and complex and/or not well structured problems; especially, multi-criteria model analysis and other non-standard simulation-and optimization-based methods and tools for model analysis.

- Methodologies for modeling and analyzing complex systems, including the integration of models, multi-agent models, methods and software for integrated assessment, subjective evaluation models, decision analysis models, and catastrophic risk management models.

- Applications of innovative methodologies to analyze complex real-world problems. Environmental, social, industrial, and financial applications were considered, including policy measures for improving the quality of the environment, and ex-ante measures for mitigating the consequences of catastrophic events.

- Software tools supporting the development of applications in the areas mentioned above.

More than 70 papers were presented during VEAM and CSM'02 Workshops. There was a major overlap of interests in these workshops: both were dealing with modeling methodologies and real-world applications.

However, the Feature Issue was not limited to these two events. The editors encouraged all OR researchers and practitioners to submit papers that present original contributions to Complex Systems Modeling that are within the scope summarized above. Finally, 33 papers have been submitted;
16 papers passed the review procedure and are presented in this Issue.

Due to the scope of the issue defined above, the presented papers cover a diversified range of topics. However, each paper deals with an innovative modeling method and/or an innovative application. All methodological papers at least outline a complex application to which the presented method has been applied. Because of the characteristics of the papers it was not practical to organize the issue by grouping papers according to any crisp classification rule. Therefore, the issue is organized into the following four parts:

1. Modeling methodologies;

2. Agent-based modeling;

3. Optimization and

4. Applications.

Each part is composed of papers whose main contribution corresponds best to the part's scope:

1. Modeling methodologies: The four papers in this part present various novel modeling paradigms which are illustrated by using real-world applications. In the first paper, J. Gu and X. Tang introduce the Meta-synthesis approach based on Chinese intellectual tradition; the paper shows how complex systems can be analyzed by an integration of various modeling techniques and synthesis of tacit knowledge of experts and decision makers. M. Makowski presents the methodological background and the implementation of a structured modeling technology developed for supporting the whole modeling process for modelbased decision-making support; the technology is implemented for huge linear models developed and used at distant locations; the applicability of this technology is illustrated by its applications to the next generation of a complex model used for supporting international negotiations aimed at improving European air quality. Z. Pawlak then follows with a new approach to conflict analysis that exploits capabilities of rough sets; although there are many formal models for conflict analysis the presented approach has attractive features 
which are illustrated by a simple tutorial example. Finally, H. Tamura discusses behavioral (descriptive) models of individual and group decision making under uncertainty, and their applicability to ethical consensus formation; the proposed approach extends Kahneman-Tversky model of prospect theory and resolve Allais and Ellsburg paradoxes.

2. Agent-based modeling: Five papers present various aspects of intelligent agent technology which is a relatively new but fast developing modeling technique. In the first paper in this part R. Schleiffer deals with the fundamental issues of intelligent agents, and presents a general agent architecture linking aspects of perception, interpretations of natural language, learning, and decision-making; the paper also summarizes characteristics of intelligence of such agents. A. Chaturvedi, S. Mehta, D. Dolk, and R. Ayer then discuss both the agent-based simulation for computational experimentation, and a methodology and an example of modeling artificial labor market; thus, the paper presents the whole agent-based modeling cycle, and shows in detail the development of a complex application. M. Ryoke and Y. Nakamori present a new method for detection of local structures in a complex database consisting of numerical and nominal attributes; agents are generated to explore dynamically changing parts of data in order to detect subsets of data and the corresponding "ifthen" rules. T. Fischer and H. Gehring deal with a multi-agent system developed for supporting planning transshipment in a seaport automobile terminal; the paper presents the complexity of the vehicle transshipment problem, and the advantages of the developed multi-agent approach. Another novel agent-based approach is discussed by T. Ma and Y. Nakamori who present a multiagent model to simulate the evolutionary process of technological innovation; the approach integrates capabilities of the two types of models that capture features of technological innovations from the macro and micro levels, respectively.

3. Optimization: This part is composed of three papers that deal with non-standard aspects of optimization techniques. First, H. Nakayama, Y. Yun, T. Asada and M. Yoon describe a multiobjective and goal programming approach (MOP/GP) to machine learning, especially to support vector machine; the approach is also effective for problems with unbalance among the data set, and for problems with additional learning. Second, O. Arndt, T. Barth, B. Freisleben and M. Grauer present a new method of using a neural network for predicting the results of a simulation system based on the Finite Element Method; the very high precision of such an approximation is integrated into optimization strategy; such a prediction-based optimization method applied to facility optimization in groundwater engineering has demonstrated a reduction of computation time by more than a half. The final paper in this part by T. Ermolieva deals with optimization-based approaches for a social security simulation model under demographic and economic uncertainties; the model is a compromise between a purely actuarial model and an overlapping generations general equilibrium model; the design of optimal robust (against uncertainties) strategies is achieved by an adaptive simulation-based optimization procedure that includes non-smooth risk functions.

4. Challenging applications: The final part presents four complex applications, three in the engineering fields, and one in the environmental policy. First, E. Antonsson and H.-J. Sebastian present a novel approach to deal with uncertainties in engineering design processes; populations of design alternatives are generated using evolutionary methods while uncertainties are simulated by variations of the fuzzy fitness functions and hybrid uncertainty fitness functions; thus, the presented approach copes with both fuzzy and probabilistic types of uncertainty, and has been applied to support robust design in several application areas. The second paper by G. Chryssolouris, N. Papakostas and D. Mourtzis deals with the scheduling of a refinery importing various types of crude oil; the paper describes a simulation based approach to the refinery operation, which is modeled as a pooling problem. L. Martins, J. Craveirinha, J. Clímaco and T. Gomes analyze a bi-dimensional dynamic routing model for alternative routing telecommunication networks; the authors present a heuristic procedure for dealing with instability of 
the underlying model; moreover, they demonstrate the improvement of the performance of the proposed routing method compared with a reference dynamic routing method. Finally, T. Masui presents an application of the AIM/Material model (one of the models of the Asia-Pacific Integrated Model) to environmental policy evaluation; a computable general equilibrium model is used for an integrated analysis of policy options in Japan aimed at addressing two related environmental problems: the GDP loss derived from the environmental constraints on $\mathrm{CO}_{2}$ reduction under the Kyoto protocol, and the reduction of final disposal of solid wastes according to the target of the Japanese government.

\section{Acknowledgements}

The Guest Editors of this Feature Issue were also the organizers of both workshops and wish to thank IIASA and JAIST for providing facilities and organizational help for the workshops. We thankfully acknowledge financial support by JISR, Kyoto, Japan for the CSM'02 workshop.

Finally, we thank the authors for their contribution and the following referees who participated in the review process: H. Appelrath, M. Ball, $\mathrm{M}$. Bastian, A. Beulens, T. Bui, C. Carlsson, A. Chaturvedi, J. Cytowski, J. Daduna, Y. Dai, J. Desroussiers, D. Dolk, W. Domschke, J. Dupacova, B. Fleischmann, R. Fourer, H. Gehring, A. Geoffrion, R. Goldberg, J. Granat, M. Grauer, J. Gu, T.
Ho, O. Hryniewicz, V. Huynh, M. Inuiguchi, S. Irnich, J. Kacprzyk, S. Kaden, M. Kainuma, P. Kall, A. Karbowski, L. Kruś, G. Laporte, A. Lewandowski, M. Luptacik, D. Mattfeld, W. Michałowski, M. Nagata, H. Nakayama, V. Norkin, M. Obersteiner, W. Ogryczak, E. Pesch, G. Pflug, C. Posthof, J. Potvin, J. Sauer, M. Scheidt, R. Schleiffer, M. Speranza, W. Stoelzle, H. Szczerbicka, E. Szczerbicki, K. Szkatula, T. Wang, H. Tamura, M. Tanaka, T. Tanino, N. Trautmann, E. Triesch, R. Vetschera, S. Voss, B. Werners, J. Wessels, A. Wierzbicki, and S. Wolff. Some of the papers have been reviewed a second time after revisions. All colleagues mentioned here reacted positively to our requests. Without their cooperation it would have not been possible to prepare this Feature Issue with the review standards of EJOR.

Marek Makowski International Institute for Applied Systems Analysis, Schlossplatz 1, Laxenburg 2361, Austria E-mail address:marek@iiasa.ac.at

Yoshiteru Nakamori Japan Advanced Institute of Science and Technology, Kanazawa, Japan E-mail address: nakamori@jaist.ac.jp

Hans-Jürgen Sebastian RWTH Aachen University, Aachen, Germany E-mail address: sebastian@or.rwth-aachen.de

Available online 25 August 2004 


\section{Additional copies}

The abstract of the article and the Editorial are available online at www.iiasa.ac.at/Publications

Hard copies are also available for a small handling charge. Orders must include the publication number and should be sent to the Publications Department, International Institute for Applied Systems Analysis, A-2361 Laxenburg, Austria.

Telephone: +432236807

Telefax: +43223671313

E-mail: publications@iiasa.ac.at 
International Institute for Applied Systems Analysis

Schlossplatz 1, A-2361 Laxenburg, Austria

Tel: +432236807 Fax: +43223671313

I I AS A www.iiasa.ac.at 